\title{
A NOTE ON TWO THEOREMS OF LEINDLER
}

\author{
JÓZSEF NÉMETH
}

Abstract. The theorem proved here is the generalization of two theorems of Leindler regarding embedding relations among classes of Fourier coefficients. The generalization is based on replacing the power functions by more general ones introduced by Mateljevič and Pavlovič.

Mathematics subject classification (2000): 26D15, 42A05, 42A10.

Key words and phrases: Inequalities, embedding relations, Fourier coefficients.

\section{REFERENCES}

[1] R. P. BOAS JR., Integrability theorems for trigonometric transforms, Springer-Verlag, Ergebnisse 38, Berlin, (1967).

[2] G. A. Fomin, A class of trigonometric series, Mat. Zametki 23 (1978), 213-222.

[3] J. W. GARRETT AND Č. V. STANOJEVIĆ, Necessary and sufficient conditions for $L^{1}$ convergence of trigonometric series, Proc. Amer. Math. Soc. 60 (1976), 68-71.

[4] A. N. Kolmogorov, Sur l'ordre de grandeur des coefficients de la série de Fourier-Lebesgue, Bull. Acad. Polon. Sci. (A), Sci. Math. (1923), 83-86.

[5] L. LEINDLER, On the equivalence of classes of Fourier coefficients, Math. Inequal. Appl. 3 (2000), 45-50.

[6] L. LeINDLER, A note on some classes of real sequences, Math. Inequal. Appl. 4 (2001), 53-58.

[7] M. MatelJeVič AND M. PAVlovič, $L^{p}$-behavior of power series with positive coefficients and Hardy spaces, Proc. Amer. Math. Soc. 87 (1983), 309-316.

[8] H. P. Mulholland, Concerning the generalization of the Young-Hausdorff theorem and the Hardy-Littlewood theorems on Fourier constants, Proc. London Math. Soc. 35 (1933), 257-293.

[9] S. SIDON, Hinreichende Bedingungen für den Fourier-character einer trigonometrischen Reihe, J. London Math. Soc. 14 (1939), 158-160.

[10] N. Singh AND K. M. Sharma, Integrability of trigonometric series, J. Indian Math. Soc. 49 (1985), 31-38.

[11] Č. V. Stanojević, Classes of $L^{1}$-convergence of Fourier-Stieltjes series, Proc. Amer. Math. Soc. 82 (1981), 209-215.

[12] Č. V. Stanojević And V. B. Stanojević, Generalizations of the Sidon-Telyakovskil theorem, Proc. Amer. Math. Soc. 101 (1987), 679-684.

[13] S. A. TELyAKOVSKII, On a sufficient condition of Sidon for integrability of trigonometric series, Mat. Zametki (Russian) 14 (1973), 317-328.

[14] Ž. TomOVSKI, An application of the Hausdorff-Young inequality, Math. Inequal. Appl. 1 (1998), 527-532.

[15] Ž. TOMOVSKI, A note on some classes of Fourier coefficients, Math. Inequal. Appl. 2 (1999), $15-18$.

[16] S. Z. A. ZENEI, Integrability of trigonometric series, Tamkang J. Math. 21 (1990), 295-301. 